\title{
Swallowing dysfunction in cancer patients
}

\author{
Dysphagia Section, Oral Care Study Group, Multinational \\ Association of Supportive Care in Cancer (MASCC)/ \\ International Society of Oral Oncology (ISOO) • \\ Judith E. Raber-Durlacher - Mike T. Brennan • \\ Irma M. Verdonck-de Leeuw • Rachel J. Gibson • \\ June G. Eilers - Tuomas Waltimo • Casper P. Bots • \\ Marisol Michelet • Thomas P. Sollecito • \\ Tanya S. Rouleau • Aniel Sewnaik • \\ Rene-Jean Bensadoun • Monica C. Fliedner • \\ Sol Silverman Jr • Fred K. L. Spijkervet
}

Received: 1 September 2011 / Accepted: 29 November 2011 /Published online: 29 December 2011

(C) The Author(s) 2011. This article is published with open access at Springerlink.com

\begin{abstract}
Purpose Dysphagia (swallowing dysfunction) is a debilitating, depressing, and potentially life-threatening complication in cancer patients that is likely underreported. The present paper is aimed to review relevant dysphagia literature between 1990 and 2010 with a focus on assessment tools, prevalence, complications, and impact on quality
\end{abstract}

J. E. Raber-Durlacher

Department of Hematology, Leiden University Medical Center,

Leiden, the Netherlands

M. T. Brennan • T. S. Rouleau

Department of Oral Medicine, Carolinas Medical Center,

Charlotte, NC, USA

e-mail: Mike.Brennan@carolinashealthcare.org

T. S. Rouleau

e-mail: Tanya.Rouleau@carolinashealthcare.org

I. M. Verdonck-de Leeuw

Department of Otorhinolaryngology, Head and Neck Surgery,

VU University Medical Center,

Amsterdam, the Netherlands

e-mail: im.verdonck@vumc.nl

\section{R. J. Gibson}

School of Medical Sciences, University of Adelaide,

Adelaide, South Australia, Australia

e-mail: rachel.gibson@adelaide.edu.au

\section{J. G. Eilers}

The Nebraska Medical Center and University

of Nebraska Medical Center,

Omaha, NE, USA

e-mail: JEilers@nebraskamed.com of life in patients with a variety of different cancers, particularly in those treated with curative chemoradiation for head and neck cancer.

Methods The literature search was limited to the English language and included both MEDLINE/PubMed and EMBASE. The search focused on papers reporting dysphagia as a side effect of cancer and cancer therapy. We identified

\section{T. Waltimo}

Institute of Preventive Dentistry and Oral Microbiology

School of Dental Medicine, University of Basel,

Basel, Switzerland

e-mail: Tuomas.Waltimo@unibas.ch

\section{P. Bots}

Department of Oral Biochemistry,

Academic Centre for Dentistry Amsterdam (ACTA),

and Centre for Special Care in Dentistry (SBT),

Amsterdam, the Netherlands

e-mail: casperbots@gmail.com

\section{Michelet}

Department of Oral Oncology,

FUNDALEU (Foundation for the Fight Against Leukemia),

Buenos Aires, Argentina

e-mail: michelet@fibertel.com.ar

\section{T. P. Sollecito}

Clinical Oral Medicine, Department of Oral Medicine,

University of Pennsylvania School of Dental Medicine,

3400 Spruce Street,

Philadelphia, PA, USA

e-mail: tps@dental.upenn.edu 
relevant literature through the primary literature search and by articles identified in references.

Results A wide range of assessment tools for dysphagia was identified. Dysphagia is related to a number of factors such as direct impact of the tumor, cancer resection, chemotherapy, and radiotherapy and to newer therapies such as epidermal growth factor receptor inhibitors. Concomitant oral complications such as xerostomia may exacerbate subjective dysphagia. Most literature focuses on head and neck cancer, but dysphagia is also common in other types of cancer.

Conclusions Swallowing impairment is a clinically relevant acute and long-term complication in patients with a wide variety of cancers. More prospective studies on the course of dysphagia and impact on quality of life from baseline to long-term follow-up after various treatment modalities, including targeted therapies, are needed.

Keywords Dysphagia $\cdot$ Aspiration · Swallowing dysfunction - Cancer - Head and neck neoplasms . Chemoradiation $\cdot$ Deglutition disorders

\footnotetext{
A. Sewnaik

Department of Otorhinolaryngology, Head and Neck Surgery, Erasmus Medical Center Rotterdam,

Rotterdam, the Netherlands

e-mail: a.sewnaik@erasmusmc.nl

\section{R.-J. Bensadoun}

Radiation Oncology Department,

Poitiers University Hospital and Faculty of Medicine,

Poitiers, France

e-mail: rene-jean.bensadoun@chu-poitiers.fr

M. C. Fliedner

ANP Oncology, Bern University Hospital,

Bern, Switzerland

e-mail: Monica.Fliedner@insel.ch

S. Silverman Jr

Department of Orofacial Sciences,

University of California San Francisco, School of Dentistry,

San Francisco, CA, USA

e-mail: sol.silverman@ucsf.edu

F. K. L. Spijkervet

Department Oral \& Maxillofacial Surgery,

University Medical Center Groningen, University of Groningen,

Groningen, the Netherlands

e-mail: f.k.1.spijkervet@kchir.umcg.nl

J. E. Raber-Durlacher $(\square)$

Section Preventive Dentistry,

Academic Centre for Dentistry Amsterdam (ACTA),

University of Amsterdam and VU University Amsterdam,

Gustav Mahlerlaan 3004,

1081 LA Amsterdam, the Netherlands

e-mail: jraber@worldonline.nl
}

\section{Introduction}

Swallowing of food and liquids including saliva is a complex biomechanical interaction of physiology and anatomy that occurs in four stages: oral preparatory, oral, pharyngeal, and esophageal $[1,2]$. The oral phases of swallowing are voluntary, followed by an involuntary reflex, requiring fast and precise coordination between sensory input and motor function controlled by the medulla in the brain stem and by the cerebral cortex. The material being swallowed is a critical factor in determining the type of swallow. For example, as the volume increases, the duration and width of opening of the upper esopharyngeal sphincter as well as the duration of airway closure increase [3]. Similarly, viscosity of the bolus affects the swallowing process. Six cranial nerves and over 25 muscles are involved, and any neurological or structural defect affects swallowing. This may result in dysphagia (swallowing dysfunction), a symptom indicating a delay in the passage of solids or liquids from the oral cavity to the stomach.

Dysphagia and odynophagia (painful swallowing) are common in cancer patients. Most studies on this complication are performed in patients with head and neck cancers (HNC), but swallowing disorders may also develop in patients with other malignancies. The current narrative review will summarize current literature on dysphagia in cancer aimed to inform health care professionals on this debilitating and potentially life-threatening complication. We will focus on assessment tools, prevalence, complications, and impact on quality of life in patients with a variety of different cancers, particularly in those treated with curative chemoradiation (CRT) for HNC. In addition, future directions of research in this area will be discussed.

\section{Methodology}

A research librarian performed literature searches using MEDLINE/PubMed and EMBASE. Search terms included dysphagia, odynophagia, aspiration, swallowing dysfunction, esophagitis, cancer, head and neck neoplasms, chemoradiation, targeted therapies, deglutition, deglutition disorders. The period searched was between 1990 and 2008, with an updated search completed by the Section Head (JRD) from 2008 to 2010, which included MEDLINE, EMBASE, and SCOPUS databases and a search of the references of relevant articles. The search focused on studies reporting dysphagia as a side effect of cancer and cancer therapy. Searches were limited to studies involving human subjects that were published in English. Both original research and review articles were considered for inclusion in this narrative review. The majority of the papers involved patients with $\mathrm{HNC}$, but a limited number of papers 
dealing with other cancers was indentified. Papers were categorized into dysphagia assessment, dysphagia in $\mathrm{HNC}$ and non-HNC, complications, and impact on quality of life.

\section{Dysphagia assessment}

Assessment of dysphagia typically includes both clinical and instrumental evaluations, whereas in some studies, the presence of a feeding tube or dietary changes are used as surrogate markers for dysphagia [4].

Clinical swallowing examination includes a medical history, oral/oropharyngeal examination, and swallow trials. Key indicators of swallowing problems include a history of swallowing complaints, incidents of coughing/choking or regurgitation, difficulty or avoidance of some food consistencies, poor nutrition, presence of a feeding tube, any prior oral/oropharyngeal resection or chemoradiation, history of pneumonia or respiratory disease, and any prior neurological problems. Oral/oropharyngeal examination involves inspection of the oral cavity and oral health including dental status (number of teeth, caries, periodontal disease), dental prosthesis, oral dryness, as well as evaluation of the strength, motion, and symmetry of the tongue, lips, jaws, and soft palate. Furthermore, sensory perception of the lips, cheeks, palate, tongue, and pharynx is evaluated. Observing symptomatic dysphagia includes a swallowing test, which incorporates trials of various food and fluid consistencies. Bolus size and characteristics (taste, temperature) can be modified to examine any change. Multiple swallows may be observed to explore fatigue effects throughout a meal.

Level of swallowing disability as determined from the clinical bedside assessment can be quantified using the Royal Brisbane Outcome Measure for Swallowing (RBHOMS) [5]. The RBHOMS is a swallowing disability rating scale, designed to monitor difficulties in everyday swallowing function based on clinical indicators of swallowing, not specific diet/fluid consistencies. Psychometric analysis reveals it to be a valid clinical tool for documenting change in swallowing disability over time and across patients with different etiologies.

Objective assessment of swallowing function and swallow safety is frequently performed using videofluoroscopy of swallowing (VFSS). It allows radiographic assessment of the structures and dynamics involved in all phases of the swallowing process. This procedure is often referred to as modified barium swallow (MBS), which is a validated instrument developed by Logemann and coworkers [6]. Patients are given measured volumes, and viscosities of food and the findings are scored with the Swallowing Performance Status Scale (SPS) [7], which provides an accurate assessment of the presence and severity of dysphagia and aspiration risk by combining clinical and radiographic data (Table 1). The Dysphagia Outcome and Severity Scale may

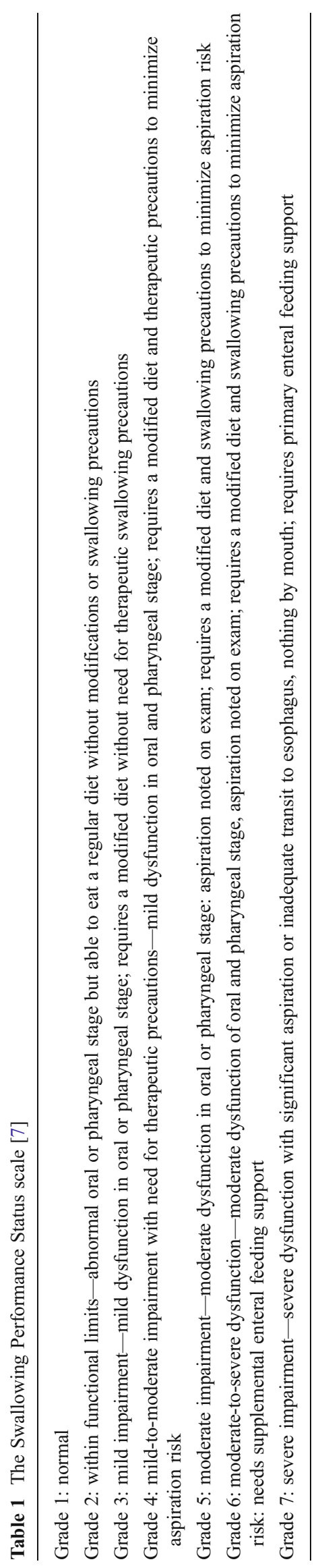


be used to document functional outcomes and diet status [8]. The penetration-aspiration scale encompasses an 8-point, equal-appearing interval scale to describe penetration and aspiration events [9]. In addition, the oropharyngeal swallow efficiency is a global measure of the safety and the speed of the swallow which is determined by measuring the percentage of bolus swallowed into the esophagus divided by the total (oral and pharyngeal) transit time. VFSS can be combined with conventional or high-resolution manometry, which permits correlation of the motility of anatomic structures with the resulting intraluminal pressure patterns. Another objective tool is Fiberoptic Endoscopic Evaluation of Swallowing (FEES). FEES visualizes the pharynx using a transnasal endoscopic tube and detects premature food or fluid leakage from the oral cavity with increased risk for aspiration, but it does not provide information on the oral stages of swallowing. FEES can be combined with sensory testing (FEESST). Direct endoscopy under anesthesia can be used to visualize (and dilate) strictures in more inferior parts of the pharynx. Computed tomography (CT) scans have a role in evaluating radiation therapy (RT)-induced thickness of several swallowing structures. Advances have been made in the digital processing of videofluoroscopic or endoscopic evaluation to derive objective measurements [10]. In addition, predictive modeling has now become available for swallowing dysfunction [11].

A number of patient- and clinician-rated scales have been developed to assess subjective dysphagia and its impact on quality of life (QOL) in cancer patients. The Swallowing Questionnaire Quality of Life questionnaire (SWAL-QOL and SWAL-CARE) [12] and the MD Anderson Dysphagia Inventory (MDADI) are validated dysphagia-specific QOL instruments. The SWAL-QOL is a 44-item QOL instrument that defines cutoff scores aimed to identify patients with dysphagia [13]. The MDADI is a validated dysphagiaspecific QOL instrument consisting of 20 questions with global, emotional, functional, and physical subscales. Other instruments with subscales or domains on dysphagia and QOL include the European Organization for Research and Treatment of Cancer (EORTC) QLQ C-30 (global quality of life scale) and Head and Neck Module, the Performance Status Scale for HNC patients (PSS-H\&N) [14], the Functional Assessment of Cancer Therapy Head and Neck Module (FACT-H\&N) [14, 15], the University of Washington Quality of Life Revised (UW-QOL-R) [16], the Head and Neck Cancer Inventory (HNCI) [17], and the University of Michigan Head and Neck Quality of Life survey (HNQOL) [18]. The Oral Mucositis Daily Questionnaire (OMDQ) [19] and the Oral Mucositis Weekly Questionnaire-Head and Neck (OMWQ-HN) are validated scales that have been developed to assess mucositis-associated mouth and throat pain, as well as its impact on function (including swallowing) and overall well-being [20]. Recently, the Vanderbilt
Head and Neck Symptom Survey (VHNSS) has been validated to screen for symptoms, including swallowing in HNC patients treated with chemoradiation [21], and the Sydney Swallow Questionnaire (SSQ) has been developed to assess self-reported physiological oral and pharyngeal swallowing function [22]. In addition, acute and chronic dysphagia can be assessed using the Common Terminology Criteria for Adverse Events (CTCAE) and the Radiation Therapy Oncology Group/European Organization for Research and Treatment of Cancer's (RTOG/EORTC) Acute and Late Radiation Morbidity Scoring System. The Therapy Outcome Measure (TOM) is a clinician-rated instrument that comprises ten scales relating to a range of communication and swallowing disorders [23]. The Head and Neck Performance Status Scale (HNPS) is also a clinician-rated instrument evaluating speech, normalcy of diet, and eating in public [24].

There is discrepancy in the literature with respect to the correlation between subjective and objective swallowing evaluation. For example, Pauloski et al. [25] reported excellent correlation between swallow function assessed by VF and patient-reported dysphagia. In contrast, Jensen et al. [26] found little concordance between dysphagia-related complaints and objective parameters. Objective evaluation may underestimate dysphagia severity experienced by patients. In reverse, patients may not report any difficulty with swallowing, but silent aspiration may occur without coughing [27]. In addition, patients may not necessarily show abnormality in all aspects of swallowing [28]. Thus, combining several subjective and objective evaluation techniques providing complimentary information is considered useful.

Swallowing outcomes can be also graded using the International Classification of Functioning, Disability and Health (ICF, WHO) [29]. The ICF describes and measures health and disability associated with different health conditions. It encompasses three domains describing impairment of body function or structure (i.e., swallow dysfunction assessed by VF or MBS), activity limitation (measured by clinician- or patient-rated scales), and participation restriction (reduced ability to be involved in work or social situations) [30]. QOL is not part of the ICF classification, but the ICF can be used to study the complex interrelationships among functioning, contextual factors, and individuals' perceptions of their QOL.

\section{Head and neck cancers}

The primary treatment modalities for $\mathrm{HNC}$ include surgery and radiotherapy, with an increasing role for chemotherapy and molecularly targeted therapies. All treatment modalities 
may result in acute and long-term swallowing dysfunction, but dysphagia may also be present prior to therapy.

\section{Pre-treatment dysphagia}

Dysphagia can be a result of malignancies in the head and neck region, particularly pharyngeal, tongue, and esophageal cancers. The frequency and severity of pre-treatment dysphagia and its sequelae (e.g., aspiration) depend on tumor stage and localization, since the tumor can affect the motility of structures involved in swallowing [31-35]. Pauloski et al. [31] reported a prevalence of pre-treatment dysphagia in $28.2 \%$ in patients with stage $\mathrm{T} 2$ or more oral cancer, $50.9 \%$ in pharyngeal cancer, and $28.6 \%$ in laryngeal cancer. Other studies also showed significant rates of pre-treatment dysphagia and aspiration (summarized in Table 2). In addition to dysphagia caused by the tumor, increased age may be associated with increased baseline swallowing dysfunction [36]. Patients who cannot swallow adequately before treatment are at greater risk for chronic swallowing dysfunction after treatment [27, 37]. However, most studies on the prevalence of chronic dysphagia begin assessment at 3 months after treatment when acute effects have resolved whereas prospective studies starting prior to cancer treatment are necessary to distinguish between tumor- and treatment-associated dysphagia.
Dysphagia following surgery

Surgical interventions for HNC result in anatomic or neurologic insults with site-specific patterns of dysphagia [38]. Transection of muscles and nerves, loss of sensation, and scar tissue may all affect functioning of tissues vital for swallowing [39]. The swallowing deficits that occur after surgical resections vary with the site of the tumor [40], the size of the tumor [41], the extent of surgical resection [42], and possibly the type of reconstruction [43]. In general, the larger the resection, the more swallowing function will be impaired. However, resection of structures vital to bolus formation, bolus transit, and airway protection such as the tongue, tongue base, and the larynx will have the greatest impact on swallowing function $[44,45]$. Resection of the anterior floor of mouth has been found to have a limited impact on swallowing function [46], except when the geniohyoid or myelohyoid muscles are involved [47]. Surgery disrupting the continuity of the mandibular arch without reconstruction has a profound negative impact on swallowing function. Resection of tumors involving the palate and maxillary sinus often creates defects that need reconstruction to restore oral function. Papers by Mittal et al. [44] and Manikantan et al. [48] provide a detailed review of surgical procedures and dysphagia and aspiration risk. Improvements in diagnostic techniques leading to refinements of indications for surgery and minimally invasive surgical

Table 2 Estimated prevalence of pre-treatment aspiration and aspiration in head and neck cancer patients

\begin{tabular}{|c|c|c|c|c|c|}
\hline Tumor stage & Study type & $\begin{array}{l}\text { Number }(N) \\
\text { of patients/ } \\
\text { controls }\end{array}$ & $\begin{array}{l}\text { Dysphagia (\%)/ } \\
\text { assessment instrument }\end{array}$ & $\begin{array}{l}\text { Aspiration }(\%) / \\
\text { assessment } \\
\text { instrument }\end{array}$ & Reference \\
\hline $\mathrm{T} 2$ or more & $\begin{array}{l}\text { Prospective } \\
\text { case/contr }\end{array}$ & $352 / 104$ & $\begin{array}{l}\text { Oral, } 28.2 \% \text {; pharynx, } \\
50.9 \% \text {; larynx, } 28.6 \% / \mathrm{VFS} \text {, MBS }\end{array}$ & & Pauloski et al. [32] \\
\hline III-IV & $\begin{array}{l}\text { Retrospective } \\
\text { survey }\end{array}$ & $\begin{array}{l}\text { 79/large } \\
\text { normative } \\
\text { group }\end{array}$ & $\begin{array}{l}\text { Mild impairment, } 28 \% \\
\text { Mild-moderate impairment, } 34 \% \\
\text { Moderate-severe, } 4 \% \\
\text { VFS, MBS, SPS }\end{array}$ & $\begin{array}{l}\text { Oral, } 14 \% \\
\text { Oropharynx, 30\% } \\
\text { Larynx, } 67 \% \\
\text { Hypopharynx, } 80 \% \\
\text { VFS }\end{array}$ & Stenson et al. [33] \\
\hline III-IV & $\begin{array}{l}\text { Prospective } \\
\text { observational study }\end{array}$ & $27 /$ no contr & & $\begin{array}{l}41 \% \\
\text { VFS }\end{array}$ & Rosen et al. [106] \\
\hline IV & $\begin{array}{l}\text { Prospective } \\
\text { observational study }\end{array}$ & 22 & & $\begin{array}{l}14 \% \\
\text { VFS }\end{array}$ & Eisbruch et al. [88] \\
\hline II-IV & Retrospective study & 63 & $\begin{array}{l}71.5 \%, \text { grade } 1-3 ; 17.5 \%, \\
\text { grade } 4-5 ; 11 \%, \text { grade } 6-7 / \\
\text { MBS, SPS }\end{array}$ & $\begin{array}{l}17 \% \\
\text { MBS/VFS }\end{array}$ & Nguyen et al. [107] \\
\hline III-IV & $\begin{array}{l}\text { Prospective } \\
\text { observational study }\end{array}$ & 36 & & $\begin{array}{l}8 \% \\
\text { VFS }\end{array}$ & Feng et al. [86] \\
\hline All tumor stages & Retrospective study & 236 & $\begin{array}{l}\text { Mild to severe dysphagia: oral, } \\
5 \% \text {; oropharynx, } 33 \% \text {; } \\
\text { larynx, } 29 \% \text {; hypopharynx, } 52 \% \\
\text { VFS, MBS, SPS }\end{array}$ & & Nguyen et al. [35] \\
\hline
\end{tabular}

Contr controls, MBS modified barium swallow procedure, SPS swallowing performance status scale, VFS videofluoroscopy

In part adapted from Platteaux et al. [53] 
techniques are promising advances to reduce dysphagia in HNC patients [49].

\section{Dysphagia associated with (chemo)radiation}

Primary radiotherapy for $\mathrm{HNC}$ is conventionally given up to a total dose of $70 \mathrm{~Gy}$ in daily fractions of $2 \mathrm{~Gy}$, five fractions a week during 7 weeks. Intensified schedules (hyperfractionation and/or acceleration) and the use of chemoradiotherapy (CRT) have been shown to have greater efficacy than surgical treatment in terms of regional control and survival in some cancers, such as tonsillar, nasopharynx, and base of tongue. CRT has become the standard of care for HNC where possible [50, 51]. However, organ preservation does not always translate into preservation of function $[44,52]$. CRT regimens have more acute and chronic side effects as compared to conventional radiotherapy alone. The severity of radiation-induced dysphagia is dependent on total radiation dose, fraction size and schedule, target volumes, treatment delivery techniques, concurrent chemotherapy, genetic factors, percutaneous endoscopic gastrostomy (PEG) tube or nil per os, smoking, and psychological coping factors (reviewed by [53]). Patients with advanced tumors seem less likely to have worsening of swallowing following CRT [54].

The most common acute oropharyngeal complications include mucositis, edema, pain, thickened mucous saliva and hyposalivation, infection, and taste loss, which may all contribute to acute odynophagia and dysphagia. By 3 months after treatment, acute clinical effects have largely resolved, and normal swallowing function is restored in the majority of patients. Unfortunately, a continuing cascade of inflammatory cytokines triggered by oxidative stress and hypoxia may damage the exposed tissues, and dysphagia may develop even years after the completion of treatment. Late sequelae that may contribute to chronic dysphagia include reduced capillary flow, tissue atrophy and necrosis, altered sensation, neuromuscular fibrosis leading to trismus and stricture formation, hyposalivation, and infection including dental diseases (e.g., radiation caries and periodontal attachment loss). Lee et al. [55] reported the results of a retrospective study of 199 patients treated with CRT. Of 82 patients who underwent swallowing evaluation, 41 (21\% of total) patients were found to have a stricture. Predictors of stricture formation included twice-per-day radiation, hypopharyngeal malignancy, and female sex. Moreover, lymphedema, radiation-induced damage to neural structures, and genetic predisposition may play a role in chronic dysphagia [11, 39].

Intensity-modulated radiotherapy (IMRT) has emerged as an effective technique to deliver the full radiation dose to the tumor and regions at risk, while reducing exposure of surrounding healthy tissues. Eisbruch and coworkers [56] have identified dysphagia and aspiration risk structures (DARS). In particular, damage to the tongue base, pharyngeal constrictors, the larynx, and autonomic neural plexus was found to be crucial in the development of post-radiotherapy dysphagia. Studies confirmed the association between reducing the radiation dose to DARS by IMRT or brachytherapy and decreasing the dysphagia risk [11, 57-61]. Roe et al. [62] performed a systematic review of the literature on swallowing outcomes following IMRT. Based on the results of 16 studies (published between 2001 and 2009), a benefit of IMRT was found, but a meta-analysis was not possible due to the heterogeneous nature of the studies. A recent longitudinal long-term follow-up study by Feng et al. [63] reported that IMRT sparing of DARS did not compromise locoregional control rates in patients with oropharyngeal cancer and was effective to reduce chronic dysphagia. Protection of the glottic larynx via beam-split IMRT techniques is promising for the prevention of aspiration [64].

Dysphagia associated with epidermal growth factor receptor inhibitors

Epidermal growth factor receptor (EGFR) is commonly overexpressed in a variety of cancers including $\mathrm{HNC}$ and is an attractive molecular target. Monoclonal antibodies and smallmolecule inhibitors have been developed to inhibit EGFR pathways. Cetuximab has been shown to enhance the effects of radiotherapy and improves survival at 5 years in patients with advanced HNC [65]. Acne-like skin rash is a frequently reported side effect of cetuximab, but most reports to date suggest that mucositis and dysphagia are not increased as compared to radiotherapy alone $[65,66]$. In contrast, a small study on concurrent RT and cetuximab in patients with locally advanced HNC found more severe mucositis and acute dysphagia than reported previously [67]. In a study that combined panitumumab, carboplatin, and paclixatel with IMRT in patients with advanced $\mathrm{HNC}$, the incidence of grade 3 mucositis and dysphagia was greater than $94 \%$ [68].

\section{Xerostomia and dysphagia}

There is evidence of the importance of saliva in the initiation and the efficiency of swallowing [69]. In normal circumstances, the swallowing process is initiated when cohesive forces between food particles in the bolus are strongest [70, 71]. Difficulty in swallowing and risk of choking may arise if peak cohesive force is not reached because of alterations in salivary flow and viscosity. Dysphagia has been reported in patients with different etiologies of salivary gland dysfunction measured by patient-reported outcomes and VF [72]. Teguh et al. [73] found a strong association between dry mouth, thick saliva, and dysphagia-related QOL. However, hyposalivation was not associated with objective swallow disturbances 12 months after CRT for HNC; rather, changes in the 
perception of swallow ability and diet choices were found to have changed [74].

A meta-analysis [75] evaluating the efficacy of amifostine, a cytoprotectant to reduce damage to salivary glands in HNC patients treated with radiation, showed a significant decrease in the prevalence of dysphagia ( $P=0.04$; odds ratio $=0.26$; confidence interval, $0.07-0.92$ ). This may be an effect of decreased mucosal toxicity leading to less fibrosis and late dysphagia, rather than an effect of reduced salivation. Brizel et al. [76] confirmed that the administration of amifostine may have a modest effect on reducing late dysphagia in patients treated with (C)RT.

\section{Non-head and neck cancers}

Acute as well as chronic dysphagia may develop in any cancer patient with oropharyngeal mucositis as a result of treatment toxicity to the esophagus or secondary infection. For example, acute dysphagia is estimated to occur in up to $20 \%$ of patients after high-dose RT and in up to $40 \%$ in patients treated with concurrent chemotherapy for lung cancer $[77,78]$. Dysphagia may also develop in patients with a wide variety of malignancies treated with targeted therapies. For example, Sonis and coworkers [79] reported dysphagia in $8.5 \%$ of patients who developed mammalian target of rapamycin-associated stomatitis. In selected cases, swallowing may be affected by the tumor itself. This is reported to occur in a small percentage of patients with lung cancer, but because of the frequency of this cancer, a large number may be affected. The most common cause of lung cancer-related dysphagia is mediastinal disease compressing the esophagus [80].

Metastatic breast cancer may occasionally involve the gastrointestinal tract and may cause swallow problems. Lobular breast carcinoma is most likely to metastasize into the oropharynx or the esophagus [81]. Dysphagia has also been described as a presenting symptom of thyroid cancer [82] or as a late side effect of treatment with radioactive iodine [83].

Swallowing may be impaired in patients with acute and chronic graft-versus-host disease (GVHD), as a result of bullous esophagitis [84]. In addition, chronic GVHD may result in submucosal fibrosis and occasionally in esophageal strictures. There may be fibrotic peri-oral skin changes, muscles may be involved, and salivary production may be impaired. Oropharyngeal swallow abnormalities assessed by VF were also found to be present in allogeneic hematopoietic stem cell transplantation (HSCT) recipients without chronic GVHD [85].

\section{Complications}

Dysphagia may predispose to aspiration (defined as swallowing dysfunction once the bolus has passed the vocal folds) and potentially life-threatening pulmonary complications [86]. Aspiration usually manifests by coughing or clearing of the throat before, during, or after swallowing, but in almost half of HNC patients, the cough reflex is ineffective or absent [87]. Silent aspiration was found to be frequent following CRT [88], but this complication as well as its consequences is underappreciated. Nguyen et al. [34] reported on 55 patients with locally advanced HNC treated with CRT; eight patients developed aspiration pneumonia, which was fatal in five cases. MBS appeared as a useful tool to assess aspiration risk [89].

Dysphagia may contribute to dehydration, which may eventually affect renal function. Reduced food intake and unfavorable dietary changes may lead to malnutrition and decreased resistance to infection. Prolonged feeding by a nasogastric feeding tube or a PEG tube may be necessary. In turn, this may contribute to sustained dysphagia, because of muscle atrophy $[52,90]$. Difficulties with speaking, eating and drinking, or drooling may affect emotional health and put patients and family members in social isolation. Opioids for the management of odynophagia may contribute to hyposalivation and constipation.

\section{Impact on quality of life}

QOL reflects the health status of patients by assessing symptoms and functioning and the psychosocial response to possible limitations. Odynophagia and dysphagia and their complications may result in a marked decrease of overall QOL and health-related (HR)QOL. Eating and drinking may become difficult or even impossible, give no pleasure, and absorb a long time. The ability of taking different types of food may be hampered, and problems with eating in public may be experienced, all of which may result in isolation and depressive symptoms. The presence of a feeding tube has been shown to be a powerful predictor of QOL 1 year post-treatment. Tube feeding is time consuming and is associated with significant costs [91]. Patients treated with CRT for oropharyngeal tumors had better emotional and functional scores of subscales of the MDADI than patients who underwent surgery followed by RT [92]. Teguh and coworkers [73] performed a study on the dose administered to swallowing structures and swallowing-related QOL. They found a clear dose-effect relationship for radiation to the superior constrictor muscle and long-term swallowing outcomes and QOL. Langendijk and coworkers [93] found HRQOL to be more seriously affected by swallowing disorders than by comparable grades of xerostomia, particularly in the first 12 months after completion of CRT for HNC. IMRT reduced morbidity including dysphagia and improved HRQOL in a prospective long-term follow-up study [94]. One study found dysphagia contributing to 
HRQOL deterioration at 6 months with improvement at 12 months, but not completely up to baseline levels in patients who underwent surgery for HNC [95]. Dysphagia in HNC has a significant impact on QOL not only in patients but also in their caregivers [96]. Dysphagia is also known as a barrier for patients to return to work after treatment [97]. A gradual worsening of symptoms including dysphagia has been reported by patients treated with high-dose CRT for lung cancer, but this had no clear impact on the overall QOL at 18 months [98].

Several limitations should be noted with respect to QOL studies in patients with $\mathrm{HNC}$ and other cancers. Many trials only report clinician-rated CTCAE scores $\geq 3$, which may not provide an adequate estimate of the burden of dysphagia [99]. Furthermore, tumor- and treatment-related symptom control issues affect the domains of physical and functional well-being, whereas differences in coping capacity may result in less consistent effects of these symptoms on social and emotional well-being [100]. In addition, dysphagia is not an isolated symptom; it rather manifests as a symptom complex that includes numerous components (e.g., oropharyngeal or esophageal pain, speech impairment, dry mouth, taste alterations, the presence of a feeding tube, coughing, pulmonary complications, altered self-image).

\section{Concluding remarks and future directions}

Swallowing impairment is a clinically relevant acute and long-term complication in patients with a variety of different cancers, particularly in those treated with curative CRT for HNC. It is important to note that CRT, which is considered to be "organ-sparing" as compared to radical surgery, does not necessarily translate into functional preservation.

Swallowing problems have a multifactorial and complex etiology, and our current insight into the prevalence of swallowing dysfunction in cancer patients is still limited. Most studies are performed in HNC patients, but the heterogeneous nature of studies with respect to design, inclusion criteria, and dysphagia assessment makes it difficult to obtain a clear insight in the prevalence and severity of dysphagia and aspiration after different treatment modalities. These conditions are likely underreported [52, 98]. Instrumental testing is crucial before, during, and after CRT in HNC patients to document swallow function and diagnose aspiration, but also, patient-reported measurements should be included. Clinicians tend to assign a lower grade of severity than patients, and even low observer-reported dysphagia rates might represent clinically significant dysphagia [100]. There is a clear need to perform prospective studies on the course of swallow functioning and impact on QOL from baseline to long term after various (new) HNC treatment modalities as well as in patients with non-HNC, particularly in those who underwent allogeneic HSCT.

Radiation therapy to the head and neck area can result in acute and long-term dysphagia that may increase in severity over time even years after the completion of radiotherapy. Advances in radiation therapy leading to more accurate delineation of radiation targets in the head and neck is an important area of investigation since this may result in better tumor control and promises reduced toxicity [57]. In addition, the use of radioprotectors such as amifostine may improve swallow outcomes. The addition of chemotherapy can increase acute toxicity including swallowing problems.

Data are inconclusive whether the addition of chemotherapy results in an increased risk of long-term dysphagia. Studies are needed to determine whether acute inflammation associated with oropharyngeal mucositis predisposes for late dysphagia. Pauloski et al. [101] reported that impaired oral intake in the first year post-CRT was associated with chronic mucosal changes. There is recent evidence from an experimental study that RT-induced mucositis is associated with fibrosis [102]. Exuberant fibrosis results in a loss of elasticity that may contribute to detrimental functional consequences, including acute and late dysphagia [39]. Agents capable of ameliorating RT- and CT-induced mucositis, particularly those that decrease inflammation and the pathogenic fibrotic repair response, may minimize late complications, including swallowing problems. More research should also be performed to determine the impact of molecular targeted therapies on swallow function in HNC patients and nonHNC patients.

Management of swallowing disorders is beyond the scope of the review, but needs evidence-based data to formulate multidisciplinary supportive care approach [103]. A systematic review indicated a positive effect of involvement of speech-language pathologists in the prevention and treatment of oropharyngeal dysphagia in cancer and non-cancer patients [28].

Screening in clinical practice to identify patients who may be in need of swallow rehabilitation should be performed routinely, but ideally, efforts are aimed at identifying risk patients and developing cost-effective preventative measures. Langendijk et al. [11] developed a predictive model for dysphagia risk after curative (C)RT. Werbrouck [60] found dose-related parameters as well as genetic polymorphisms in DNA repair genes to be predictive for acute dysphagia. More studies into genetic profiles associated with enhanced or reduced toxicity risk are warranted. Sonis [104] suggested that when a patient develops one complication as a result of cancer treatment, it is likely that he/she will develop other toxicities in a predictable pattern [105]. Studies into symptom clusters of acute and chronic toxicities, including C(RT), and targeted therapy-induced dysphagia may help to better understand common pathobiological 
mechanisms, which may lead to more effective management strategies. Looking at symptom clusters rather than at isolated symptoms seems also important to evaluate the total burden to patients and to estimate costs.

Acknowledgments We thank Tainika Williams, Department of Oral Medicine, Carolinas Medical Center, Charlotte, NC, USA, for her help with the literature search.

Conflict of interest The authors have none to declare.

Open Access This article is distributed under the terms of the Creative Commons Attribution Noncommercial License which permits any noncommercial use, distribution, and reproduction in any medium, provided the original author(s) and source are credited.

\section{References}

1. Logemann JA (1997) Role of the modified barium swallow in management of patients with dysphagia. Otolaryngol Head Neck Surg 116:335-338

2. Garden AS, Lewin JS, Chambers MS (2006) How to reduce radiation-related toxicity in patients with cancer of the head and neck. Curr Oncol Rep 8:140-145

3. Logemann JA (2007) Swallowing disorders. Best Pract Res Clin Gastroenterolog 21:563-573

4. Cheng S, Bradford CR, Ronis DL (2006) Variables associated with feeding tube placement in patients with head and neck cancer. Arch Otolaryngol Head Neck Surg 132:655-661

5. Ward EC, Conroy AL (1999) Validity, reliability and responsiveness of the Royal Brisbane Hospital Outcome Measure for Swallowing. Asia Pac J Speech Lang Hear 4:109-129

6. Logemann JA, Rademaker AW, Pauloski BR et al (1998) Normal swallowing physiology as viewed by videofluoroscopy and videoendoscopy. Folia Phoniatr Logop 50:311-319

7. Karnell MP, McCracken E (1994) A data base information storage and reporting system for videofluorographic oropharyngeal motility (OPM) swallowing evaluations. Am J Speech Language Pathol 3:54-60

8. O’Neil KH, Purdy M, Falk J et al (1999) The dysphagia outcome and severity scale. Dysphagia 14:139-145

9. Rosenbek JC, Robbins JA, Roecker EB, Coyle JL, Wood JL (1996) A penetration-aspiration scale. Dysphagia 11:93-98

10. Kahrilas PH, Lin S, Rademaker AW, Logemann JA (1997) Impaired deglutive airway protection. Gastroenterology 113:1457-1464

11. Langendijk JA, Doornaert P, Rietveld DHF, Verdonck-de Leeuw IM, Leemans CR, Slotman BJ (2009) A predictive model for swallowing dysfunction after curative radiotherapy in head and neck cancer. Radiother Oncol 90:189-195

12. McHorney CA, Robbins J, Lomax K et al (2002) The SWALQOL and SWAL-CARE outcomes tool for oropharyngeal dysphagia in adults: III. Documentation of reability and validity. Dysphagia 17:97-114

13. Rinkel RN, Verdonck-de Leeuw IM, Langendijk JA et al (2009) The psychometric and clinical validity of the SWAL-QOL questionnaire in evaluating swallow problems experienced by patients with oral and oropharyngeal cancer. Oral Oncol 45:e67-e71

14. List M, D'Antonio L, Cella D et al (1996) The Performance Status Scale for head and neck cancer patients and the Functional Assessment of Cancer Therapy-Head and Neck Scale: a study of utility and validity. Cancer 77:2294-2301
15. Cella DF, Wiklund I, Shumaker SA, Aaronson NK (1993) Integrating health-related quality of life into cross-national clinical trials. Qual Life Res 2:433-440

16. Weymuller EA, Alsarraf R, Yueh B, Deleyiannis FW, Coltrera MD (2001) Analysis of the performance characteristics of the University of Washington Quality of Life instrument and its modification (UW-QOL-R). Arch Otolaryngol Head Neck Surg 127:489-493

17. Funk GF, Karnell LH, Christenen AJ, Moan PJ, Ricks J (2003) Comprehensive head and neck oncology health status assessment. Head Neck 25:561-567

18. Terrell JE, Nanavati KA, Esclamado RM, Bishop JK, Bradford CR, Wolf GT (1997) Head and neck cancer-specific quality of life: instrument validation. Arch Otolaryngol Head Neck Surg 123:1125-1132

19. Stiff PJ, Bensinger EH, Emmanoullides C et al (2006) Reliability and validity of a patient self-administered daily questionnaire to assess impact of oral mucositis (OM) on pain and daily functioning in patients undergoing autologous hematopoietic stem cell transplantation (HSCT). Bone Marrow Transplant $37: 393-401$

20. Epstein JB, Beaumont JL, Gwede CK et al (2007) Longitudinal evaluation of the oral mucositis weekly questionnaire-head neck cancer, a patient-reported outcomes questionnaire. Cancer 109:1914-1922

21. Murphy BA, Dietrich MS, Wells N et al (2010) Reliability and validity of the Vanderbilt Head and Neck Symptom Survey: a tool to assess symptom burden in patients treated with chemoradiation. Head Neck 32:26-37

22. Dwivedi RC, Rose SST, Roe JWG et al (2010) Validation of the Sydney Swallow Questionnaire (SSQ) in a cohort of head and neck cancer patients. Oral Oncol 46:e10-e14

23. Enderby PM, John A (1999) Therapy outcome measures in speech and language therapy: comparing performance between different providers. Int J Lang Commun Disord 34:417-429

24. List MA, Ritter-Sterr C, Lansky SB (1990) A performance status scale for head and neck cancer patients. Cancer 66:564-569

25. Pauloski BR, Rademaker AW, Logemann JA et al (2002) Swallow function and perception of dysphagia in patients with head and neck cancer. Head Neck 24:555-565

26. Jensen K, Bonde JA, Grau C (2006) The relationship between observer-based toxicity scoring and patient assessed symptom severity after treatment for head and neck cancer. A correlative cross sectional study of the DAHANCA toxicity scoring system and the EORTC quality of life questionnaires. Radiother Oncol 78:298-305

27. Lewin JS (2007) Dysphagia after chemoradiation: prevention and treatment. Int J Radiat Onc Biol Phys 69:S86-S87

28. Speyer R, Baijens L, Heijnen M, Zwijnenberg I (2010) Effects of therapy in oropharyngeal dysphagia by speech and language therapists: a systematic review. Dysphagia 25:40-65

29. WHO (2001) The international classification of functioning disability and health (ICF). WHO, Geneva

30. Frowen JJ, Perry AR (2006) Swallowing outcomes after radiotherapy for head and neck cancer: a systematic review. Head Neck 28:932-944

31. Logemann JA, Rademaker AW, Paulowski BR et al (2006) Site of disease and treatment protocol as correlates of swallow function in patients with head and neck cancer treated with chemoradiation. Head Neck 28:64-73

32. Pauloski BR, Rademaker AW, Logemann JA et al (2000) Pretreatment swallowing function in patients with head and neck cancer. Head Neck 22:474-482

33. Stenson KM, MacCracken E, List M et al (2000) Swallowing function in patients with head and neck cancer prior to treatment. Arch Otolaryngol Head Neck Surg 126:371-377 
34. Nguyen NP, Moltz CC, Frank C et al (2004) Dysphagia following chemoradiation for locally advanced head and neck cancer. Ann Oncol 15:383-388

35. Nguyen NP, Vos P, Moltz CC et al (2008) Analysis of the factors influencing dysphagia severity upon diagnosis of head and neck cancer. Br J Radiol 81:706-710

36. Martin-Harris B, Brodsky MB, Michel Y et al (2005) Breathing and swallowing dynamics across the adult life span. Arch Otolaryngol Head Neck Surg 131:762-770

37. Dirix P, Abbeel S, Vansraelen B, Hermans R, Nuyts S (2009) Dysphagia after chemoradiotherapy for head-and-neck squamous cell carcinoma: dose-effect relationships for the swallowing structures. Int J Radiat Oncol Biol Phys 75:385-392

38. Kronenberger MB, Meijers AD (1994) Dysphagia following head and neck surgery. Dysphagia 9:236-244

39. Murphy BA, Gilbert J (2009) Dysphagia in head and neck cancer patients treated with radiation: assessment, sequelae and rehabilitation. Semin Radiat Oncol 19:35-42

40. Pauloski BR, Rademaker AW, Logemann JA, Colangelo LA (1998) Speech and swallowing in irradiated and non-irradiated post surgical oral cancer patients. Otolaryngol Head Neck Surg 118:616-624

41. Denk DM, Schima W, Eibenberger K (1997) Prognostic factors for swallowing rehabilitation following head and neck cancer surgery. Acta Otolaryngol 117:769-774

42. McConnel F, Rademaker AW, Pauloski BR et al (1994) Surgical variables affecting postoperative swallow efficiency in oral cancer patients: a pilot study. Laryngoscope 104:87-90

43. Martini DV, Lucente FE, Slavit DH (1997) Swallow and pharyngeal function in post-operative cancer patients. Ear Nose Throat $\mathrm{J}$ 76:450-456

44. Mittal BB, Pauloski BR, Haraf DJ et al (2003) Swallowing dysfunction-preventative and rehabilitation strategies in patients with head-and-neck cancers treated with surgery, radiotherapy, and chemotherapy: a critical review. Int J Radiation Oncol Biol Phys 57:1219-1230

45. Borggreven PA, Verdonck-de Leeuw I, Rinkel RN et al (2007) Swallowing after major surgery of the oral cavity or oropharynx: a prospective and longitudinal assessment of patients treated by microvascular soft tissue reconstruction. Head Neck 29:638-647

46. Jacobson MC, Franssen E, Fliss DM et al (1995) Free forearm flap in oral reconstruction. Arch Otolaryngol Head Neck Surg 121:959-964

47. Hirano M, Kuroiwa Y, Tanaka S et al (1992) Dysphagia following various degrees of surgical resection for oral cancer. Ann Otol Rhinol Laryngol 101:138-141

48. Manikantan K, Khode S, Sayed SI et al (2009) Dysphagia in head and neck cancer. Cancer Treat Rev. doi:10:10,1016/j.ctrv.2009.08.008

49. de Bree R, Leemans CR (2010) Recent advances in surgery for head and neck cancer. Curr Opin Oncol 22:186-193

50. Nuyts S, Dirix P, Clement PM et al (2008) Impact of adding concomitant chemotherapy to hyperfractionated radiotherapy for advanced head and neck cancer squamous cell carcinoma. Int $\mathrm{J}$ Radiat Oncol Biol Phys 73:1088-1095

51. Pignon JP, Le Maitre A, Bourhis J (2007) Meta-analyses of chemotherapy in head and neck cancer (MACH-NC): an update. Int J Radiol Oncol Biol Phys 69(2 Suppl):S112-S114

52. Rosenthal D, Lewin J, Eisbruch A (2006) Prevention and treatment of dysphagia and aspiration after chemoradiation for head and neck cancer. J Clin Oncol 24:2636-2643

53. Platteaux N, Dirix P, Dejaeger E, Nuyts S (2010) Dysphagia in head and neck cancer patients treated with chemoradiotherapy. Dysphagia 25:139-152

54. Salama JK, Stenson KM, List MA (2008) Characteristics associated with swallowing changes after concurrent chemotherapy and radiotherapy in patients with head and neck cancer. Arch Otolaryngol Head Neck Surg 134:1060-1065
55. Lee WT, Akst LM, Adelstein DJ et al (2006) Risk factors for hypopharyngeal/upper esophageal stricture formation after concurrent chemoradiation. Head Neck 28:808-812

56. Eisbruch A, Schwartz M, Rasch C et al (2004) Dysphagia and aspiration after chemoradiotherapy for head and neck cancer: which anatomic structures are effected and can they be spared by IMRT? Int J Radiol Oncol Biol Phys 60:1425-1439

57. Feng M, Eisbruch A (2007) Future issues in highly conformal radiotherapy for the head and neck cancer. J Clin Oncol 8:10091013

58. Fua TF, Corry J, Milner AD et al (2007) Intensity-modulated radiotherapy for nasopharyngeal carcinoma: clinical correlation of dose to the pharyngo-esophageal axis and dysphagia. Int $\mathrm{J}$ Radiat Oncol Bio Phys 67:976-981

59. Eisbruch A, Levendag PC, Feng FY, Teguh D et al (2007) Can IMRT or brachytherapy reduce dysphagia associated with chemoradiotherapy of head and neck cancer? The Michigan and Rotterdam experiences. Int J Radiat Oncol Biol Phys 69 (2 Suppl):S40-S42

60. Werbrouck J, De Ruyck K, Duprez F et al (2009) Acute normal tissue reactions in head-and-neck cancer patients treated with IMRT: influence of dose and association with genetic polymorphisms in DNA DSB repair genes. Int J Radiat Oncol Biol Phys 73:1187-1195

61. Caudell JJ, Schaner PE, Desmond DA et al (2010) Dosimetric factors associated with long-term dysphagia after definitive radiotherapy for squamous cell carcinoma of the head and neck. Int J Radiat Oncol Biol Phys 76:403-409

62. Roe JC, Carding PN, Dwivedi R et al (2010) Swallowing outcomes following intensity modulated radiation therapy. Oral Oncol 46:727-733

63. Feng FY, Kim HM, Lyden T et al (2010) Intensity-modulated chemoradiotherapy aiming to reduce dysphagia in patients with oropharyngeal cancer: clinical and functional results. J Clin Oncol 28:2732-2738

64. Schwartz DL, Hutcheson K, Barringer D, Tucker SL, Kies M, Holsinger FC, Ang KK, Morrison WH, Rosenthal DI, Garden AS, Dong L, Lewin JS (2010) Candidate dosimetric predictors of long-term swallowing dysfunction after oropharyngeal intensitymodulated radiotherapy. Int J Radiat Oncol Biol Phys 78:13561365

65. Bonner JA, Harari PM, Giralt J et al (2010) Radiotherapy plus cetuximab for locoregionally advanced head and neck cancer: 5 year survival from a phase 3 randomized trial, and relation between cetuximab-induced rash and survival. Lancet Oncol 11:21-28

66. Curran D, Giralt J, Harari PM et al (2007) Quality of life in head and neck cancer patients after treatment with high dose radiotherapy alone or in combination with cetuximab. J Clin Oncol 25:2191-2197

67. Pryor DI, Porceddu SV, Burmeister BH et al (2008) Enhanced toxicity with concurrent cetuximab and radiotherapy in head and neck cancer. Radiother Oncol 90:172-176

68. Wirth LJ, Allen AM, Posner MR et al (2010) Phase I dosefinding study of paclitaxel with panituzemab, carboplatin and intensity-modulated radiotherapy in patients with locally advanced squamous cell cancer of the head and neck. Ann Oncol 21:342-347

69. Pedersen AM, Bardow A, Beier Jensen S, Nauntofte B (2002) Saliva and gastrointestinal functions of taste, mastication, swallowing and digestion. Oral Dis 8:117-129

70. Prinz JF, Lucas PW (1995) Swallow thresholds in human mastication. Arch Oral Biol 40:401-403

71. Hamlet S, Faull J, Klein B et al (1997) Mastication and swallowing in patients with postirradiation xerostomia. Int J Radiat Oncol Biol Phys 37:789-796 
72. Rhodus NL, Moller K, Colby S, Bereuter J (1995) Dysphagia in patients with three different etiologies of salivary dysfunction. Ear Nose Throat J 74:45-48

73. Teguh DN, Levendag PC, Noever I, van Rooij P, Voet P, van der Est H, Sipkema D, Sewnaik A, Baatenburg de Jong RJ, de la Bije D, Schmitz PI (2008) Treatment techniques and site considerations regarding dysphagia-related quality of life in cancer of the oropharynx and nasopharynx. Int J Radiat Oncol Biol Phys 15:1119-1127

74. Logemann JA, Pauloski BR, Rademaker AW, Lazarus CL, Mittal B, Gaziano J, Stachowiak L, MacCracken EM, Newman LA (2003) Xerostomia: 12-month changes in saliva production and its relationship to perception and performance of swallow function, oral intake, and diet after chemoradiation. Head Neck $25: 432-437$

75. Sasse AD, Sasse EC, Alark ACC (2005) Amifostine reduces side effects and improves complete response rate during radiotherapy: results of a meta-analysis. Int J Radiat Oncol Biol Phy 64:784-794

76. Brizel J, Glatzel M, Muecke R, Micke O, Bruns F (2007) Influence of amifostine on late radiation-toxicity in head and neck cancer-a follow-up study. Anticancer Res 27:1953-1956

77. De Ruysscher D, Dehing C, Bremer RH et al (2007) Maximal neutropenia during chemotherapy and radiotherapy is significantly associated with the development of acute radiation-induced dysphagia in lung cancer patients. Ann Oncol 18:909-916

78. Dehing-Oberije C, De Ruysscher D, Petit S et al (2010) Development, external validation and clinical usefulness of a practical prediction model for radiation-induced dysphagia in lung cancer patients. Radiother Oncol 79:455-461

79. Sonis S, Treister N, Chawla S et al (2010) Preliminary characterization of oral lesions associated with inhibitors of mammalian target of rapamycin in cancer patients. Cancer $116: 210-215$

80. Camidge DR (2001) The causes of dysphagia in carcinoma of the lung. JR Soc Med 94:567-672

81. Nazareno J, Taves D, Preiksaitis HG (2006) Metastatic breast cancer to the gastrointestinal tract: a case series and review of the literature. World J Gastroenterol 12:6219-6224

82. Varsamidakis N, Kanakis M, Thomas T (2009) Dysphagia as the presenting symptom of thyroid cancer. Exp Clin Endocrinol Diabet 117:511-513

83. Almeida JP, Sanabria AE, Lima EN, Kowalski LP (2011) Late side effects of radioactive iodine on salivary gland function in patients with thyroid cancer. Head Neck (in press)

84. Akpek G, Chinratanalab W, Lee LA, Torbenson M, Hallick JP, Anders V, Vogelsang GB (2003) Gastrointestinal Involvement in chronic graft-versus-host disease: a clinicopathologic study. Biol Blood Marrow Transpl 9:46-51

85. Schima W, Pokieser P, Fordtinger C et al (1994) Videofluoroscopy of the pharynx and esophagus in chronic graft-versus-host disease. Abdom Imaging 19:191-194

86. Feng FY, Kim HM, Lyden TH et al (2007) Intensity-modulated radiotherapy of head and neck cancer aiming to reduce dysphagia: early dose-effect relationships for the swallowing structures. Int $\mathbf{J}$ Radiat Oncol Biol Phys 68:1289-1298

87. Nguyen NP, Moltz CC, Frank C et al (2007) Effectiveness of the cough reflex in patients with aspiration following radiation for head and neck cancer. Lung 185:243-248

88. Eisbruch A, Lyden T, Bradford CR et al (2002) Objective assessment of swallowing dysfunction and aspiration after radiation concurrent with chemotherapy for head and neck cancer. Int J Radiat Oncol Biol Phys 53:23-38

89. Nguyen NP, Frank C, Moltz CC, Karlsson U, Nguyen PD, Ward HW, Vos P, Smith HJ, Huang S, Nguyen LM, Lemanski C, Ludin A, Sallah S (2009) Analysis of factors influencing dysphagia severity following treatment of head and neck cancer. Anticancer Res 29:3299-3304
90. Mekhail TM, Adelstein DJ, Rybicki LA et al (2001) Enteral nutrition during the treatment of head and neck carcinoma: is a percutaneous endoscopic gastronomy tube preferable to a nasogastric tube? Cancer 91:1785-1790

91. Murphy BA (2007) Clinical and economic consequences of mucositis induced by chemotherapy and/or radiotherapy. J Support Oncol 5(Suppl 4):13-21

92. Gillespie MB, Brodsky MB, Day TA, Lee FS, Martin-Harris B (2004) Swallowing-related quality of life after head and neck cancer treatment. Laryngoscope 114:1362-1367

93. Langendijk JA, Doornaert P, Verdonck-de Leeuw I, Leemans CR, Aronson NK, Slotman BJ (2008) Impact of late treatment-related toxicity on quality of life among patients with head and neck cancer treated with radiotherapy. J Clin Oncol 26:3770-3776

94. Vergeer MR, Doornaert PAH, Rietveld DHF, Leemans CR, Slotman BJ, Langendijk JA (2009) Intensity-modulated radiotherapy reduces radiation-induced morbidity and improves health related quality of life: results of a nonrandomized prospective study using a standardized follow-up program. Int J Radiat Oncol Biol Phys $74: 1-8$

95. Borggreven PA, Aaronson NK, Verdonck-de Leeuw IM et al (2007) Quality of life after surgical treatment for oral and oropharyngeal cancer: a prospective longitudinal assessment of patients reconstructed by a microvascular flap. Oral Oncol 43:1034-1042

96. Verdonck-de Leeuw IM, Eerenstein SE, Van der Linden MH, Kuik DJ, de Bree R, Leemans CR (2007) Distress in spouses and patients after treatment for head and neck cancer. Laryngoscope 117:238-241

97. Verdonck-de Leeuw IM, van Bleek WJ, Leemans CR, de Bree R (2010) Employment and return to work in head and neck cancer survivors. Oral Oncol 46:56-60

98. Hutcheson KA, Barringer DA, Rosenthal DI, May AH, Roberts DB, Lewin JS (2008) Swallowing outcomes after radiotherapy for laryngeal carcinoma. Arch Otolaryngol Head Neck Surg 134:178-183

99. Pijls-Johannesma M, Houben R, Boersma L, Grutters J, Seghers K, Wanders R, De Ruysscher D (2009) High-dose radiotherapy or concurrent chemotherapy in lung cancer patients only induces a temporary, reversible decline in QoL. Radiother Oncol 91:443-448

100. Gluck I, Feng FY, Lyden T et al (2010) Evaluating and reporting dysphagia in trials of chemoirradiation for head-and-neck cancer. Int J Radiat Oncol Biol Phys 77:727-733

101. Pauloski BR, Rademaker AW, Logemann JA et al (2010) Relation of mucous membrane alterations to oral intake during the first year after treatment for head and neck cancer. Head Neck. doi:10.1002/hed.21542

102. Murray LA, Kramer MS, Hesson DP et al (2010) Serum amyloid $\mathrm{P}$ ameliorates radiation-induced oral mucositis and fibrosis. Fibrogenesis Tissue Repair 3:11, At: http://www.fibrogenesis. com/content $/ 3 / 1 / 11$. Accessed 3 Jan 2011

103. Murphy BA (2009) Advances in quality of life and symptom management for head and neck cancer patients. Curr Opin Oncol $21: 242-247$

104. Sonis ST (2010) New thoughts on the initiation of mucositis. Oral Dis 16:597-600

105. Aprile G, Ranoni M, Keefe D, Sonis ST (2009) Links between regimen-related toxicities in patients being treated for colorectal cancer. Curr Opin Support Palliat Care 3:50-54

106. Rosen A, Rhee TH, Kaufman R (2001) Prediction of aspiration in patients with newly diagnosed untreated advanced head and neck cancer. Arch Otolaryngol Head Neck Surg 127:975-979

107. Nguyen NP, Frank C, Moltz CC et al (2006) Aspiration rate following chemoradiation for head and neck cancer: an underreported occurrence. Radiother Oncol 80:302-306 